\title{
Water Dispersible Sulfo-Polyester Resins with Controlled Nano-Sized Particles
}

\author{
Guerino G. Sacripante and Daniel A. Foucher \\ Department of Chemistry \& Biology, Ryerson University, 350 Victoria Street, Toronto ON M5B 2K3 \\ Canada \\ E-mail: gsacripante@ryerson.ca
}

\begin{abstract}
Water dispersible polyester resins derived from dimethyl terephthalate, dimethyl

5sulfoisophthalate sodium salt, 1,2-propane diol and diethylene glycol were prepared. A Design of Experiment (DOE) was explored by varying the concentration of the ionic 5sulfoisophthalate sodium salt and diethylene glycol at various molecular weights and found to correlate with particle size dispersion of the sulfonated resins in water. An empirical model for the resin glass transition was also obtained through experimental design.
\end{abstract}

Keywords: water-dispersible polymers; polyesters; nanoparticles

\section{Introduction}

Alkali sulfonated polyester resins have been known since the 1960 's, ${ }^{1}$ and their waterborne dispersions have been developed since the 1970 ' $\mathrm{s}^{2}$ for applications in adhesives, ${ }^{3}$ fibers, ${ }^{4}$ inks, ${ }^{5}$ cosmetics ${ }^{6}$ and a variety of specialty coatings. ${ }^{7}$ The main hydrophilic component of the polyester resin is the alkali 5-sulfo-3,5-isophathalate moiety, and depending on its concentration, can render the resin from fully soluble in water or as colloids ranging from nano to micro size dispersions. ${ }^{8}$ The most common alkali is the monovalent sodium, potassium, or lithium ion, but the divalent magnesium $\left(\mathrm{Mg}^{2+}\right)$, zinc $\left(\mathrm{Zn}^{2+}\right)$, calcium $\left(\mathrm{Ca}^{2+}\right)$ or multivalent iron $\left(\mathrm{Fe}^{3+}\right)$ can also be utilized to obtain larger sized dispersions. The term "waterborne" is often used interchangeably with other descriptors such as water-dissipatable, -dispersible or dispellable. These terms refer to the activity that render the polyester to either fully dissolve to form an aqueous solution, or to disperse in water as a colloid (dispersion). Additionally, it is also possible to have both soluble and colloidal fractions present in the same solution. The random incorporation of 5sodiosulfoisophthalate units within the polyester backbone results in self-stabilized aqueous particle/colloid dispersions without the need of additional surfactants. The polyester dispersions are in a solvated molecular form, and since the ionic groups are randomly distributed along the backbone, it is unlikely that a classical micelle structure is formed. Such micelles would consist of the charged groups residing on the surface of a particle with the hydrophobic segments occupying the interior. As such, these colloids can coalesce to form films upon water evaporation and this technique is used in many coating applications. ${ }^{9}$ Alternatively, self-assembly of such units into compact nano- or micron-sized aggregates in water, when exposed to multivalent electrolytes such as divalent cations (i.e. $\mathrm{Zn}^{2+}$ ), can be utilized. These materials can then be collected as dry particles after filtration. ${ }^{10}$

The water-dispersible sulfonated polyesters are odorless, typically amorphous, and derived from the melt condensation of the above-mentioned alkali dimethyl 5-sulfo-3,5isophathalate $\mathrm{Na}^{+}$monomer, together with organic diacids and diols. The organic diacids are typically aromatic in origin (e.g., terephthalic or isophthalic) to yield moderate to high glass transition temperature $\left(\mathrm{T}_{\mathrm{g}}\right)$ polymers, or aliphatic diacids for lower $\mathrm{T}_{\mathrm{g}}$ or semi-crystalline resins. The diol components are usually selected from short-chain carbon diols such as 
ethylene glycol, propylene glycol or diethylene glycol, as well as longer chain polyethylene-glycol. ${ }^{11}$ Higher carbon chain units such as neopentyl glycol or cyclohexane-dimethanol are selected for more rigid or hydrolytically stable polymers. The sulfonated polymers are typically prepared by dispersing the solid in water at a temperature of about 10 to $30^{\circ} \mathrm{C}$ above the $\mathrm{T}_{\mathrm{g}}$ of the resin. The concentration of polymer in water may vary, and its miscibility/ dispersibility depends on its degree of polymerization and alkali sulfonated content. Branched polymers can also be made using appropriate multifunctional organic alcohols or acids such trimethylol propane, pentaerythritol, or trimellitic acid. These additives impart broader molecular weight and/or modified visco-elastic properties.

Our interest in these sulfonated polyester resins was to generate a relationship of resin composition with dispersion properties in the range of 5 to 150 nanometers $(\mathrm{nm})$. This model should be extremely useful for many applications, particularly for the self-assembly of polymers with desired particle sizes. ${ }^{12}$ The resin monomer composition to obtain these desired properties was selected as dimethyl 5sulfoisophthalate sodium salt (DM-5-SISP-Na $\left.{ }^{+}\right)$, dimethyl terephthalate (DMT), 1,2-propanediol (1,2-PG) and diethylene glycol (DEG). It is known that 5-SISP-Na ${ }^{+}$ concentration is primarily responsible for the waterdispersibility of the resin, but the concentration of the lower carbon and more hydrophilic diol, especially diethylene glycol, also influences dispersibility of the resin. Using these monomers as a model system, the relationship between their molecular composition and resin properties such as dispersion size and $\mathrm{Tg}$ are explored through Design of Experiments (DOE).

\section{Experimental Section}

\subsection{Materials}

Dimethyl 5-sulfoisophthalate sodium salt (>98\%), dimethyl terephthalate (>99\%), 1,2-propanediol $(>99.5 \%)$, and diethylene glycol were obtained from Sigma Aldrich (99\%). The catalyst, n-butyl stannoic acid (FASCAT 4100) was obtained from Brenntag. All reagents were utilized without further purification.

\subsection{Characterization}

The softening point was obtained using the Mettle FP83HT Dropping point apparatus using 0.5 grams of sample heated at $10 \mathrm{oC} / \mathrm{min}$. Molecular weights were estimated using Gel permeation chromatography (GPC) performed using a Waters APC 2695 equipped with a refractive index detector calibrated with polystyrene standards and THF as the eluting solvent. Thermal transitions were recorded using the TA Instruments Q1000 differential scanning calorimeter (DSC) in a temperature range from 0 to $150{ }^{\circ} \mathrm{C}$ at a heating rate of 10
${ }^{\circ} \mathrm{C} / \mathrm{min}$ under nitrogen flow. The melting and glass transition temperatures were collected during the second heating scan and reported as the onset. The particle size of the resulting dispersion was measured using Honeywell MICROTRAC RTM UPA150 particle size analyzer.

\subsection{Synthesis for the Preparation of the Sulfo-polyester (Scheme 1)}

Example. Polyester Resin 2. A resin was synthesized from 1.25 mole $\%$ of DM-5-SISP-Na ${ }^{+}, 48.75$ mole\% of DMT, 47.5 mole $\%$ of PG and 5 mole\% of DEG. Note that 1 mole equivalent excess of 1,2-propanediol was also utilized for the transesterification, and which on polycondensation was removed by distillation.

To a 1 Liter Parr reactor equipped with a mechanical stirrer, distillation apparatus, and bottom drain valve was added DM5-SISP-Na+ (14.8 g: $50 \mathrm{mmol})$ of , DMT (378.7 g: $1.95 \mathrm{~mol})$, PG (289.1 g: $3.8 \mathrm{~mol})$, DEG (21.2 g: $0.2 \mathrm{~mol})$ and FASCAT 4100 (0.5 g, $2.3 \mathrm{mmol})$. The mixture was heated to $160{ }^{\circ} \mathrm{C}$ during a $30 \mathrm{~min}$. period, and mixing was started slowly until all the solids melted and then increased to $100 \mathrm{rpm}$. Methanol $(\mathrm{MeOH})$ started to condense, and the temperature was then increased to $185^{\circ} \mathrm{C}$ during a $3 \mathrm{~h}$ period and maintained for an additional $1 \mathrm{~h}$ during which time the condensate (125 g) was collected in the distillation receiver. The gas chromatograph of this condensate indicated $\sim 98.5 \% \mathrm{MeOH}$ and $\sim 1.5 \% 1,2-\mathrm{PG}$. The temperature was then increased to $195{ }^{\circ} \mathrm{C}$ and after about $2 \mathrm{~h}$, the pressure was decreased slowly from atmospheric to $\sim 3 \mathrm{~mm} \mathrm{Hg}$ (i.e., $400 \mathrm{kPa}$ ) over a $1 \mathrm{~h}$ period, and then maintained for an additional $90 \mathrm{~min}$. Samples were then taken periodically until a softening point of about 110 and $125^{\circ} \mathrm{C}$ was obtained, after which the reactor was repressurized to ambient with $\mathrm{N}_{2}$, and all of the contents discharged through the bottom drain into a pan and left cool to room temperature (RT). This process yielded samples 2a and 2b. During the latter polycondensation, about $65 \mathrm{~g}$ of condensate was collected in the distillation receiver and measured by gas chromatograph to contain $~ 98 \%$ 1,2-PG, $\sim 1.5 \% \mathrm{MeOH}$ and $\sim 0.5 \% \mathrm{DEG}$. The cooled resin product was slightly yellow colored and transparent (amorphous). GPC analysis indicated that sample $\mathbf{2 a}$ had a molecular weight of 2150 Dalton (Da), and sample $\mathbf{2 b}$ had a Molecular weight of 4956 Da. DSC analyses indicated Tg of 39.6 oC for sample $\mathbf{2 a}$ and $59.6{ }^{\circ} \mathrm{C}$ for sample $\mathbf{2 b}$. A portion of the sample $\mathbf{2 b}$ was then ground to coarse particles $(>5 \mu \mathrm{m})$ using a coffee grinder and then dissipated in water (10\% by weight) by heating and stirring the mixture at about $75{ }^{\circ} \mathrm{C}$ for about $20 \mathrm{~min}$. The resulting dispersion was measured using MICROTRAC RTM UPA150 particle size analyzer yielding a particle size $\left(\mathrm{d}_{50}\right)$ of $65.0 \mathrm{~nm}$. 
<smiles>COC(=O)c1ccc(C(=O)OC)cc1</smiles><smiles>CC(O)CO</smiles><smiles>COC(=O)c1cc(C(=O)OC)cc([S+]([O])([O])[O-])c1</smiles>

DM-5-SISP-Na+

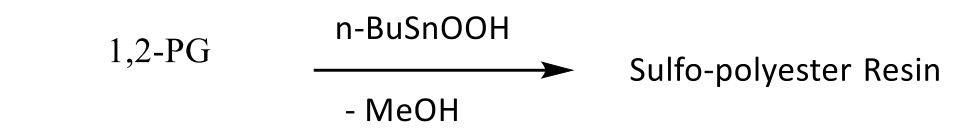<smiles>OCCOCCO</smiles>

DEG

Scheme 1. Synthesis of the sulfo-polyester Resin from DMT, DM-5-SISP Na+, 1,2-PG and DEG.

\section{Results and Discussion}

An initial DOE was explored to probe the limits of water dispersibility of the resin by selecting the two factors at two levels $\left(2^{2}\right)$; the first factor was the sulfonated monomer (5-SISP- $\mathrm{Na}^{+}$) at three different concentrations in equivalent mole percentage of the corresponding polymer (1.25 and 3.75 mole \%): and the second factor was the DEG monomer at three different concentrations in equivalent mole percentage of the corresponding polymer $(0$ and 7.5 mole $\%)$. The resin was produced by melt condensation polymerization until a molecular weight of about $5 \times 10^{3}$ $\left( \pm 2 \times 10^{2}\right)$ Daltons (Da) was obtained. This was achieved by the taking samples during the polymerization and quickly tested them with a Mettler FP83HT apparatus until the resin reached a softening point of about $125^{\circ} \mathrm{C}$. This ensures that the degree of polymerization was kept constant throughout all experiments. This was independently confirmed by the molecular weight data from GPC. The sulfo-polyester resins were then dispersed in water at a temperature of about 75 to $85{ }^{\circ} \mathrm{C}$ for about $20 \mathrm{~min}$. The results from this DOE are depicted in Table 1.

Resin sample $\mathbf{1 b}$ with the lowest sulfonation (1.25 mole \%) and no DEG content could not be effectively dispersed in water and remained as large coarse particles. On the other extreme, the highest concentration of sulfonation (3.75 mole\%) and 0 mole\% of DEG (Sample 3), resulted in some detectable small size particles, but was largely soluble, and at 7.5 mole\% DEG (Sample 4, was fully soluble in water. As shown in Table 1, the $\mathrm{T}_{\mathrm{g}}$ increased with an increasing amount of DEG and decreased with increased sulfonation content.
TABLE 1. DOE comprised of 2 factors at 2 levels

\begin{tabular}{cccccc}
\hline $\begin{array}{c}\text { Resin } \\
\text { Sample }\end{array}$ & $\begin{array}{c}5- \\
\text { SISPNa } \\
\left(\mathrm{mole}^{+}\right)\end{array}$ & $\begin{array}{c}\text { DEG } \\
(\text { mole\% })\end{array}$ & $\begin{array}{c}\mathrm{Mw}^{\mathrm{a}} \\
(\mathrm{Da}) \\
\mathrm{x} 10^{3}\end{array}$ & $\begin{array}{c}\mathrm{P.S}^{\mathrm{b}} \\
(\mathrm{nm})\end{array}$ & $\begin{array}{c}\mathrm{Tg} \\
\left({ }^{\circ} \mathrm{C}\right)\end{array}$ \\
\hline $\mathbf{1 b}$ & 1.25 & 0 & 5.11 & $\mathrm{nd}^{\mathrm{c}}$ & 62.9 \\
$\mathbf{2 b}$ & 1.25 & 7.5 & 4.96 & 65 & 54.3 \\
$\mathbf{3}$ & 3.75 & 0 & 4.85 & $<2.1$ & 59.0 \\
$\mathbf{4}$ & 3.75 & 7.5 & 4.90 & $\mathrm{~s}^{\mathrm{d}}$ & 49.1 \\
\hline
\end{tabular}

${ }^{\mathrm{a}} \mathrm{Mw}$ (Molecular Weight). ${ }^{\mathrm{b}}$ P.S. (Particle Size). ${ }^{\mathrm{c}}$ nd (not detectable. ${ }^{\mathrm{d}} \mathrm{s}$ (soluble).

For the next DOE, it was decided to narrow the sulfonation (5-SISPNa+) concentration from 1.25 and $2.5 \mathrm{~mole} \%$ and expand the DEG range to include 2.5 and 7.5 mole $\%$. We also decided to look at the effect of $\mathrm{Mw}$ on P.S. and therefore took samples at about $2 \times 10^{3}\left( \pm 2 \times 10^{2}\right)$ and $5 \times$ $10^{3}\left( \pm 2 \times 10^{2}\right) \mathrm{Da}$. A total of 24 experiments resulted from a full factorial orthogonal design of the three factors comprised of (i) sulfonation at three levels $(1.25,1.75$ and $2.5 \mathrm{~mole} \%$ ), (ii) DEG at four levels $(0,2.5,5.0$ and 7.5 mole $\%)$ and Mw at two levels $\left(\approx 2 \times 10^{3}\right.$ and $\left.\approx 5 \times 10^{3} \mathrm{Da}\right)$. The results from the DOE are depicted in Table 2. At 1.25 mole $\%$ sulfonation, the resin samples $\mathbf{1 a}, \mathbf{1 b}, \mathbf{5 a}$ and $\mathbf{5 b}$, at DEG at 0 and $2.5 \mathrm{~mole} \%$, were found not to disperse in water, whereas at 5 mole\% DEG (Samples 6a, $6 \mathbf{b}$ and 2a) partially dispersion was observed which resulted in a relatively broad distribution. At 7.5 mole\% DEG and lower $\mathrm{Mw}$, the resin sample 7a, did disperse but resulted in broad 
distribution. At the higher sulfonation level and higher DEG content, samples 10b, 13b, 14a and 14b resulted in water soluble resins.

TABLE 2. Expanded DOE

\begin{tabular}{|c|c|c|c|c|c|}
\hline $\begin{array}{c}\text { Resin } \\
\text { Sample }\end{array}$ & $\begin{array}{c}5- \\
\text { SISPNa }^{+} \\
(\operatorname{mole} \%)\end{array}$ & $\begin{array}{c}\text { DEG } \\
(\text { mole } \% \\
\text { ) }\end{array}$ & $\begin{array}{l}\mathrm{Mw}^{\mathrm{a}} \\
(\mathrm{Da}) \\
\times 10^{3}\end{array}$ & $\begin{array}{l}\text { P.S } \\
(\mathrm{nm})\end{array}$ & $\begin{array}{l}\mathrm{Tg} \\
\left({ }^{\circ} \mathrm{C}\right)\end{array}$ \\
\hline $1 a$ & 1.25 & 0 & 2.06 & $\mathrm{nd}^{\mathrm{c}}$ & 45.9 \\
\hline 1b & 1.25 & 0 & 5.11 & $\mathrm{nd}^{\mathrm{c}}$ & 62.9 \\
\hline $5 a$ & 1.25 & 2.5 & 2.21 & $\mathrm{nd}^{\mathrm{c}}$ & 42.0 \\
\hline $6 a$ & 1.25 & 2.5 & 5.10 & $\mathrm{nd}^{\mathrm{c}}$ & 62.5 \\
\hline $2 a$ & 1.25 & 5 & 2.01 & $>500^{\mathrm{e}}$ & 39.6 \\
\hline $2 b$ & 1.25 & 5 & 4.96 & $>300^{\mathrm{e}}$ & 56.6 \\
\hline $7 a$ & 1.75 & 0 & 2.11 & $295^{\mathrm{e}}$ & 30.5 \\
\hline $7 b$ & 1.75 & 0 & 5.00 & 64.9 & 54.3 \\
\hline $8 a$ & 1.75 & 2.5 & 1.89 & $250^{\mathrm{e}}$ & 50.7 \\
\hline $8 b$ & 1.75 & 2.5 & 5.10 & 105 & 61.0 \\
\hline $9 a$ & 1.75 & 5 & 2.05 & 45.2 & 33.1 \\
\hline $9 b$ & 1.75 & 5 & 5.11 & 14.4 & 57.0 \\
\hline $10 a$ & 1.75 & 7.5 & 2.19 & 15.9 & 28.9 \\
\hline $10 b$ & 1.75 & 7.5 & 5.21 & $\mathrm{~s}^{\mathrm{d}}$ & 54.5 \\
\hline $11 a$ & 2.5 & 0 & 2.10 & 65.0 & 53.3 \\
\hline 11b & 2.5 & 0 & 4.98 & 76.1 & 58.9 \\
\hline $12 a$ & 2.5 & 2.5 & 2.00 & 23.6 & 47.1 \\
\hline $12 \mathrm{~b}$ & 2.5 & 2.5 & 4.89 & 7.5 & 56.6 \\
\hline $13 a$ & 2.5 & 5 & 1.98 & 11.4 & 42.7 \\
\hline $13 b$ & 2.5 & 5 & 5.10 & $\mathrm{~s}^{\mathrm{d}}$ & 53.8 \\
\hline $14 a$ & 2.5 & 7.5 & 2.15 & $\mathrm{~S}^{\mathrm{d}}$ & 38.4 \\
\hline $14 b$ & 2.5 & 7.5 & 4.89 & $\mathrm{~s}^{\mathrm{d}}$ & 50.5 \\
\hline
\end{tabular}

${ }^{a}$ Mw (Molecular Weight). ${ }^{b}$ P.S. (Particle Size). ${ }^{c}$ nd (not detectable. ${ }^{\mathrm{d}} \mathrm{s}$ (soluble). e broad distribution/ not completely dispersed.

The $\mathrm{T}_{\mathrm{g}}$ data was analysed in an Historical Design Analysis Mode utilizing the SigmaZone Quantum XL ${ }^{\circledR}$ software for the above DOE (Table 2). The results from this regression (Table 3), resulted with the following transfer equation:

$\mathrm{T}_{\mathrm{g}}\left({ }^{\circ} \mathrm{C}\right)=49.0+0.73\left(5-\mathrm{SISPNa}^{+}\right)-6.31(\mathrm{DEG})+$

$9.03 \mathrm{Mw}-2.88\left(5-\mathrm{SISPNa}^{+}\right)(\mathrm{Mw})+$

$2.45(\mathrm{DEG})(\mathrm{Mw})$

with an $R^{2}=959$, adjusted $R^{2}=0.948$, standard error of 2.36 and orthogonality of 1.0 .

TABLE 3. Results from the $T_{g}$ DOE analysis

\begin{tabular}{|c|c|c|c|c|}
\hline Factor & $\begin{array}{l}\text { Coeff } \\
\text { icient }\end{array}$ & S.E. ${ }^{a}$ & $\begin{array}{c}p \text { - } \\
\text { Value }\end{array}$ & $\underset{b}{\text { Ortho }}$ \\
\hline Constant & 49 & 0.48 & 0 & - \\
\hline 5-SISPNa ${ }^{+}$ & 0.73 & 0.59 & 0.23 & 1.0 \\
\hline DEG & -6.31 & 0.65 & 0 & 1.0 \\
\hline Mw & 9.03 & 0.54 & 0 & 1.0 \\
\hline $\begin{array}{l}(5-S I S P N a \\
(\mathbf{M w})\end{array}$ & -2.88 & 0.66 & 0 & 1.0 \\
\hline (DEG) (Mw) & 2.45 & 0.74 & 0 & 1.0 \\
\hline
\end{tabular}

From the coefficient of the transfer function, the concentration of DEG and molecular weight has the highest effect on $\mathrm{T}_{\mathrm{g}}$, and sulfonation $\left(5-\mathrm{SISPNa}^{+}\right)$has the least effect. The two-way interaction terms had some effect in the model as well. This can be visualized with a Pareto chart (Figure 1a).

Although, the Tg values can be calculated from Fox and Flory-Fox equations, our empirical model shows similar relationship of $\mathrm{Mw}$ weight and DEG mole fraction.

A 3D surface plot of the glass transition temperature (Tg) was also obtained (Figure 1b) by the software using the most influential parameters of Molecular Weight and DEG concentration.

Since our interest were to generate a model for water dispersible resins in the size range of 5 to $150 \mathrm{~nm}$, we selected the twelve resin samples in Table 2 that resulted in our size range of interest (2b, $7 \mathbf{b}$ to $12 \mathbf{a}$ and $11 \mathbf{a}$ to $\mathbf{1 3 a}$ ), for further DOE analysis utilizing the SigmaZone Quantum XL® software. 
a

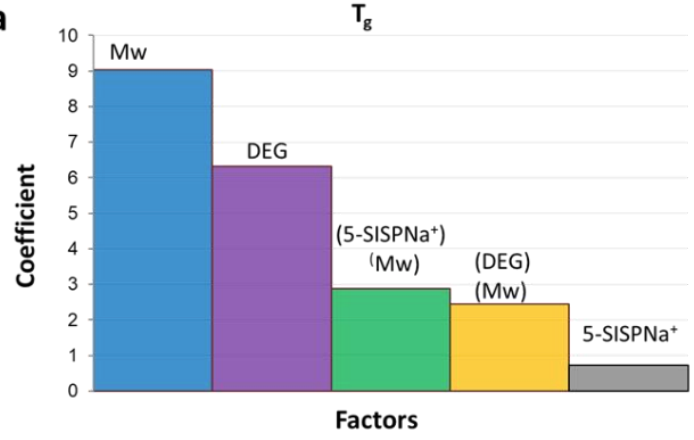

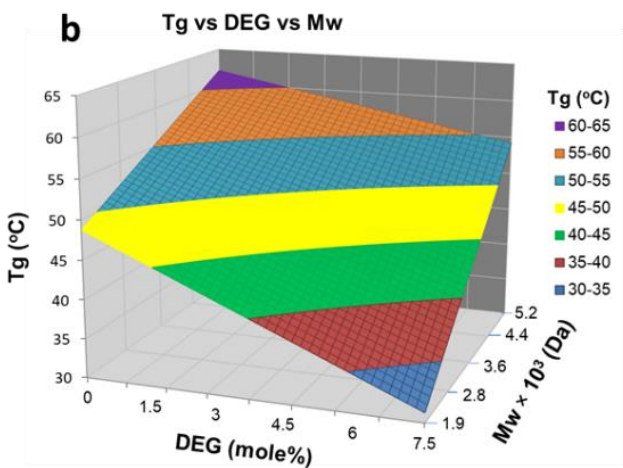

e
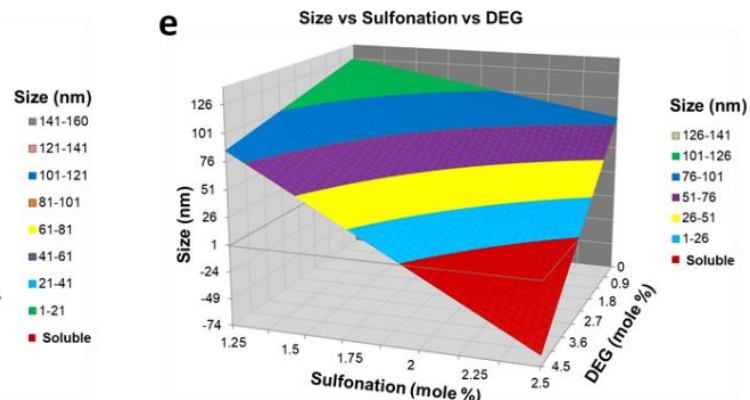

Size $(\mathrm{nm})$
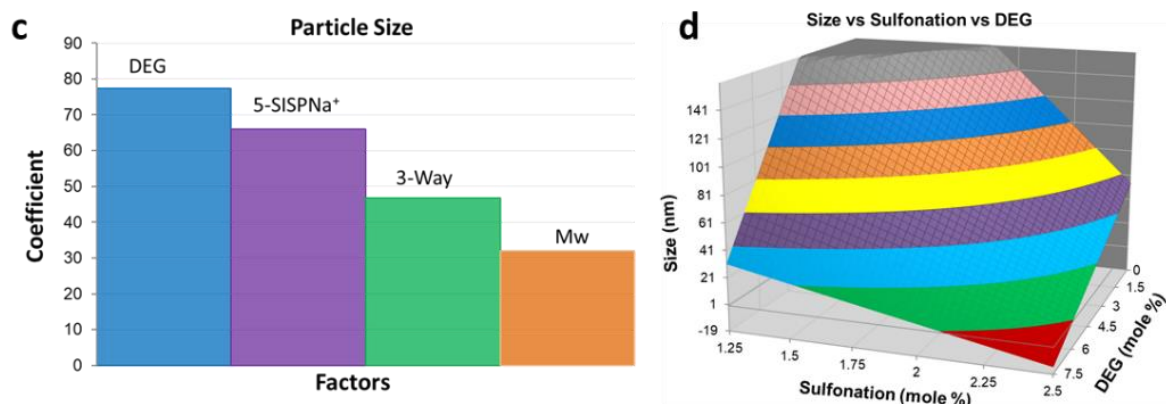

Figure 1. (a) Pareto chart of coefficients for $\mathrm{T}_{\mathrm{g}}$ (b) 3D surface plot of $\mathrm{T}_{\mathrm{g}}$ from $\mathrm{DEG}$ and $\mathrm{Mw}$ (c) Pareto chart of coefficients for Size (d) 3D surface plot at low $\mathrm{M}_{\mathrm{w}}\left(2 \times 10^{3} \mathrm{Da}\right)(\mathrm{e}) 3 \mathrm{D}$ surface plot at high $\mathrm{M}_{\mathrm{w}}\left(5 \times 10^{3} \mathrm{Da}\right)$

TABLE 4. Results from the P.S. DOE analysis

\begin{tabular}{|c|c|c|c|c|}
\hline Factor & $\begin{array}{l}\text { Coeff } \\
\text { icient }\end{array}$ & S.E. ${ }^{a}$ & $\begin{array}{c}p- \\
\text { Value }\end{array}$ & $\begin{array}{c}\text { Ortho } \\
\mathrm{b}\end{array}$ \\
\hline Constant & 56.3 & 3.97 & 0 & - \\
\hline 5-SISPNa ${ }^{+}$ & -66.0 & 7.22 & 0 & 1.80 \\
\hline DEG & -77.5 & 7.70 & 0 & 2.06 \\
\hline Mw & -32.1 & 5.49 & 0 & 1.91 \\
\hline 3-way ${ }^{c}$ & -46.8 & 10.1 & & 1.70 \\
\hline
\end{tabular}

The results from this regression (Table 4), indicated the following transfer equation:

P.S. $(\mathrm{nm})=56.3-66.0\left(5-\mathrm{SISPNa}^{+}\right)$

- 77.5 (DEG) - 32.1 9.03 Mw

$-46.8\left(5-\mathrm{SISPNa}^{+}\right)(\mathrm{Mw})(\mathrm{DEG})$

with an $\mathrm{R}^{2}=942$, adjusted $\mathrm{R}^{2}=0.909$, standard error of 12.7, but with less orthogonality (1.7-2.06)
From the coefficients of the transfer function, higher concentration of diethylene glycol, and sulfonation level decreased the particle size in water. Increasing the molecular weight also had an effect in slightly decreasing the particle size. The three-way interaction factor was important and depicted in Figure 1c, as a Pareto Chart.

The surface plots of the particle size was also from the Quantum XL® software by using the most influential parameters of sulfonation $\left(5-\mathrm{SISPNa}^{+}\right)$and DEG concentration at both the low Mw of $2 \times 10^{3} \mathrm{Da}$ (Figure 1d) and at the higher Mw of $5 \times 10^{3} \mathrm{Da}$ (Figure 1e).

The above models can be useful to predict the polyester composition, such that we attain any particle size in the nano range (5 to $150 \mathrm{~nm}$ ) as well as $\mathrm{T}_{\mathrm{g}}$ and $\mathrm{Mw}$ to some degree. The particle size control can be useful for many applications, especially wherein self-assembly is desired

\section{Acknowledgements}

This work was supported by the NSERC Discovery grant program.

\section{References}

[1] Griffing J M and Remington W R 1962 U S Patent 3018272 
[2] Shields J R, Hawkins J S and Wooten W C 1970 U S Patent 3546008

[3] (a) Evans E F and Pierce N C 1972 U S Patent 3671379 (b) Haile W A, George S E, Hale W R and Jenkins W L 2012 U S Patent 8247335

[4] Chen K M, and Liu H J, J 1987 Appl Polym Sci 34 1879

[5] Foucher D A, Sacripante G G, Wong R W and Breton M P 1999 U S Patent 5969003

[6] Sacripante G G, Goredama A, Chopra N, Zhou K and Breton M P 2016 U S Patent 9427392

[7] Blount W W 1990 U. S. Patent 4910292

[8] Kotera N and Takahashi K 1990 Bull Chem Soc Jpn 632288

[9]

https://www.eastman.com/Literature_Center/A/ADD4605 .pdf

[10] Mayer F, Sacripante G G, Zwartz, E G, Mihai, and Agur E.E 2004 U S Patent 7208253.

[11] Lin L H, Chiang C Y, Liu, H J and Chen K M 2002 J App Polym Sci 862727

[12] Sacripante, G G and Mikkelsen J C, 1999 U S Patent 5989629 